\title{
A formação do professor de matemática: metodologia sequência fedathi(sf)
}

\author{
Maria José Costa dos Santos
}

\begin{abstract}
Resumo
Este trabalho tem como objetivo analisar as contribuições da metodologia Sequência Fedathi (SF) durante uma formação com professores que lecionam matemática nos anos iniciais do ensino fundamental. Participaram da formação estudantes de graduação e pós-graduação, professores das redes de ensino municipal e estadual. Para acompanhar os cursistas na plataforma TelEduc e ministrar as oficinas, foram selecionados 5 formadores (mestrandos e doutorandos) do eixo de pesquisa ensino de matemática. Os dados apresentados foram colhidos dos relatos dos cursistas e formadores nos fóruns de discussão, portfólios na plataforma e também a partir das observações durante as oficinas de matemática. Consequentemente almejamos uma formação docente que envolva não só compreensões para o conteúdo, pois discussões sobre currículo e ensino de qualidade são essenciais para o alcance da práxis docente. Com efeito, os professores e formadores consideram que a formação foi importante para o seu crescimento profissional e que a vivência da SF Ihes proporcionou pensar a prática a partir de um aprender fazendo. Concluímos que uma formação nos pressupostos da SF conduz a um caminho que leva o pensamento à ação, e, portanto, entendemos que nesse caminhar, a metodologia vivenciada mostrou-se eficiente.
\end{abstract}

Palavras-chave:

metodologia sequência Fedathi; ensino de Matemática; formação inicial; oficinas pedagógicas. 


\section{The Formation of the Professor of Mathematics: Fedathi Sequence Methodology (SF)}

Abstract: This work aims to analyze the contributions of the Fedathi Sequence (SF) methodology during a formation with teachers who teach mathematics in the initial years of elementary school. Undergraduate and postgraduate students, teachers of the municipal and state education networks participated in the training. In order to accompany the trainers on the TelEduc platform and to minister the workshops, 5 trainers (masters and doctoral students) were selected from the mathematics teaching research axis. The data presented were collected from the reports of the trainees and trainers in the discussion forums, portfolios on the platform and also from the observations during the mathematics workshops. Consequently, we aim for a teaching formation that involves not only understanding of the content, because discussions about curriculum and quality teaching are essential for the achievement of teaching practice. Indeed, the teachers and trainers consider that the training was important for their professional growth and that the experience of the SF gave them to think the practice from a learning by doing. We conclude that a formation in the assumptions of SF leads to a path that leads thought to action, and therefore we understand that in this walk, the methodology lived proved to be efficient.

Key words: Fedathi sequence methodology; mathematics teaching; initial formation; pedagogical offices.

\section{La formation de l'instituteur de Mathématique: Méthodologie Séquence Fedathi (SF)}

Résumé: Ce travail a pour but d'analyser les contributions de la méthodologie Fedathi séquence (SF) lors de la formation des instituteurs qui enseignent les mathématiques dans les premières années de l'école primaire. On a participé dans la formation des étudiants de premier cycle de formation (licence) et de deuxième cycle (masters), des enseignants des réseaux municipaux d'éducation et de l'État. Pour suivre les participants au cours de la plateforme TELEDUC et livrer les ateliers on a sélectionné 5 formateurs (masters et doctorants) de l'axe de la recherche sur l'enseignement des mathématiques. Les données présentées ont été recueillies à partir des rapports des étudiants et des enseignants et des formateurs dans les forums de discussion, des portfolios sur la plateforme et à partir aussi des observations pendant les ateliers de mathématiques. Par conséquent nous envisageons une formation des enseignants qui consiste à comprendre non seulement au contenu, étant donné que les discussions sur les programmes d'études et une éducation de qualité sont essentiels à la réalisation de la praxis de l'enseignement. En effet, les enseignants et les formateurs considèrent que la formation a été importante pour leur croissance professionnelle et que l'expérience de SF a réfléchi la pratique d'un apprentissage par la pratique. Nous concluons qu'une formation basée sur les hypothèses SF puisse conduire à un chemin qui mène la pensée à l'action, et par conséquent, nous croyons que dans cette promenade, la méthodologie expérienciée a été efficace.

Mots-clés: méthodologie séquence Fedathi; l'enseignement des mathématiques; la formation initiale; ateliers éducatifs.

\section{La formación del profesor de matemáticas: Metodología Secuencia Fedathi (SF)}

Resumen: Este trabajo tiene como objetivo analizar las contribuciones de la metodología Secuencia Fedathi (SF) durante una formación con profesores que enseñan matemáticas en los años iniciales de la enseñanza fundamental. Participaron de la formación estudiantes de graduación y postgrado, profesores de las redes de enseñanza municipal y estadual. Para acompañar a los cursistas en la plataforma TelEduc y ministrar los talleres, fueron seleccionados 5 formadores (maestrandos y doctorandos) del eje de investigación enseñanza de matemáticas. Los datos presentados fueron recolectados de los informes de los cursistas y formadores en los foros de discusión, portafolios en la plataforma y también a partir de las observaciones durante los talleres de matemáticas. En consecuencia, anhelamos una formación docente que involucra no sólo comprensiones para el contenido, pues discusiones sobre currículo y enseñanza de calidad son esenciales para el alcance de la praxis docente. En efecto, los profesores y formadores consideran que la formación fue importante para su crecimiento profesional y que la vivencia de la SF les proporcionó pensar la práctica a partir de un aprendizaje haciendo. Concluimos que una formación en los presupuestos de la SF conduce a un camino que lleva al pensamiento a la acción, y por lo tanto entendemos que en ese caminar, la metodología vivenciada se mostró eficiente.

Palabras clave: metodología secuencia Fedathi; enseñanza de matemática; formación inicial; talleres pedagógicos. 


\section{Introdução}

A Matemática representa uma área de conhecimento complexa, sendo assim, relacionar o que se aprende com o que se ensina tem sido um desafio para a prática pedagógica de muitos professores. Para estudiosos da formação docente, como Pimenta (1997) a atividade docente é sempre práxis, uma vez que esta ação deve necessariamente pressupor a afirmação de uma intencionalidade, que direciona e dá sentido à ação, e pode modificar o objeto no sentido de sua intencionalidade em função do conhecimento visando à transformação a partir da realidade social.

Carr (1996) considera que a práxis é uma forma de ação reflexiva que pode modificar a teoria que a determina e pode transformar a prática que a concretiza, no movimento em que nem a teoria, nem a prática tem primazia, cada uma transforma e revisa continuamente a outra. Já Freire (1987) considera a práxis como uma construção revolucionária que se realiza no diálogo crítico entre educador e educando, visando a superação das condições opressoras e alienantes que impedem aos sujeitos a conquista de sua liberdade.

A formação docente que apresentamos aqui pressupõe diversas discussões, que submerge a qualidade do ensino e da aprendizagem matemática, e envolve analogamente, a ideia de práxis a qual contribui para entendermos uma formação pautada na metodologia SF.

Essa investigação seguiu os pressupostos da pesquisa empírica de caráter experimental, com foco na observação, investigação e experimentação. Com esse desenho investigativo, esse texto foi pensado para apresentar uma ação formativa, a partir do recurso didático das oficinas pedagógicas de matemática, baseada nos pressupostos metodológicos da SF, mas observando para a essencialidade da discussão: (i) a formação inicial; (ii) os efeitos do currículo e da avaliação de matemática; (iii) os modelos de ensino de qualidade em debate; e, (iv) o recurso das oficinas pedagógicas.

A seguir detalhamos os pressupostos da SF e a formação docente para o ensino de Matemática, considerando os desafios, obstáculos e possibilidades didáticas para um ensino de qualidade.

\section{A metodologia Sequência Fedathi: vivências exitosas}

A Sequência Fedathi é uma metodologia de ensino, idealizada pelo Prof. Dr. Hermínio Borges Neto, coordenador do Laboratório de Pesquisa Multimeios-MM (http:// www.multimeios.ufc.br), e tem como princípio pedagógico e formativo a mudança de postura do docente, a partir de ações que coloquem o aluno em situação de aprendizagem. É direcionada para a melhoria da práxis pedagógica visando à postura adequada do professor, e pode ser utilizada em diversas áreas de conhecimento partindo 
da premissa de que uma construção deve ser executada, integrando o projeto teórico e prático em ações didáticas concretas. A SF tem como princípio teórico contribuir para que o professor supere os obstáculos epistemológicos e didáticos que ocorrem durante a abordagem dos conceitos matemáticos em sala de aula.

Para Bachelard (2002), um obstáculo não só causa a estagnação da construção do pensamento científico, mas também contribui para o seu retrocesso. Na SF esses obstáculos são relevantes, pois interferem diretamente no ensino e na aprendizagem dos conceitos matemáticos, colaborando no trabalho matemático do estudante.

Nas aulas de matemática, a SF enuncia na ação docente, que uma situação-problema deve conduzir o estudante a passar pelas etapas do trabalho de um matemático, assim, ele deve: a) interpretar os dados da situação que the foi apresentada; b) desenhar e desenvolver as variáveis que se apresentam na solução; e, c) testar e validar as soluções conjuntamente com o professor - a prova, e isso ocorre, frente a um processo investigativo que ouse uma formação nessa direção.

Polya (1978), propunha a resolução de problemas e o desenvolvimento heurístico como uma didática reflexiva no ensino de matemática, fundamentada na heurística de resolução de um problema, em quatro fases: a) Compreender o enunciado; b) Planejar a resolução; c) Resolver o problema; e, d) Verificar a solução. Para o autor resolver problemas é uma habilidade prática, como nadar, esquiar ou tocar piano, você pode aprendê-la por meio de imitação e prática, por exemplo, se você quer aprender a nadar você tem de ir à água e se você quer se tornar um bom 'resolvedor de problemas', tem que resolver problemas.

A SF considera relevante colocar o estudante na posição de um matemático, por meio do processo de investigação (pesquisar) e resolução de problemas, a fim de estabelecer a relação entre ensino e aprendizagem (educar) a partir das necessidades de trabalho do professor. Em Polya a centralidade de sua proposta está no desenvolvimento de estratégias de resolução de problemas dos estudantes, na SF a centralidade está na maturação e vivência do problema pelo aluno, valorizando mais o processo e menos no resultado.

Na SF o papel do professor no ensino de matemática, a partir de situação-problema, é propor ao aluno que o mesmo tenha uma experiência significativa de ensino, a partir de uma experiência matemática expressiva que não apresente o saber matemático, estruturado apenas como produção intelectual, mas também como uma estrutura cultural que envolve a própria compreensão e os significados do que é ser um matemático, com seus desafios e dificuldades.

A importância da SF para o trabalho do professor fica mais evidente, ao pensarmos sobre as aulas de Matemática, pois é comum o professor lançar uma situação-problema e resolvê-la em seguida sem dar oportunidade ao estudante de experimentar, isso para a SF é inconcebível, pois uma das principais contribuições dessa metodologia, 
são as fases em que ela divide o trabalho do professor e do aluno em sala de aula, são elas: tomada de posição, maturação, solução e prova, sendo que as fases da maturação e da solução, são as que possibilitam os estudantes a compreenderem melhor os conceitos, para enfim (re)construí-los.

Santos (2007) destaca que o uso da SF em formações docentes tem se mostrado eficiente, e os professores que passam por essa perspectiva formativa destacam que as condições e possibilidades metodológicas para o trabalho significativo de matemática favorece mudanças no comportamento docente proporcionando a valorização da investigação em sala de aula. Sobre essas contribuições da SF no ensino de Matemática, destacamos os trabalhos de Santos (2007) e Lima (2007) por serem os primeiros a discutirem a formação inicial e o ensino de matemática com o uso da SF, a partir de oficinas pedagógicas.

Lima (2007) em sua pesquisa de doutorado "A matemática na formação do pedagogo: oficinas pedagógicas e a plataforma TelEduc na elaboração dos conceitos" investigou a contribuição da SF na constituição de conceitos matemáticos básicos: número, sistema de numeração decimal, operações fundamentais, geometria e medidas. O estudo foi realizado na formação inicial do pedagogo utilizando oficinas pedagógicas e a plataforma virtual TelEduc Multimeios. A pesquisa foi desenvolvida com 42 alunos da disciplina Ensino de Matemática nas Séries Iniciais do Ensino Fundamental, oferecida pelo Curso de Pedagogia da Universidade Federal do Ceará-UFC, nos semestres de 2005.2 e 2006.1.

A autora enfatiza que o estudo proporcionou aos alunos uma reflexão sobre como lidar com a Matemática na escola, numa perspectiva de um ensino melhor e de qualidade, possibilitou uma discussão mais aprofundada dos conteúdos, desconstruindo conceitos preestabelecidos, em muitos casos, equivocados. Ela constatou que as discussões, orientações e sugestões vivenciadas no curso favoreceram aos estudantes uma análise crítica das atitudes de seus antigos professores que tiveram na sua vida escolar, revelando que o tratamento dado à Matemática - difícil, incompreensível, inacessível, cheio de fórmulas - foi bem diferente da abordagem na disciplina.

Já Santos (2007) em sua pesquisa de mestrado trabalhou a Sequência Fedathi e o reaprender frações por meio de oficinas pedagógicas, a fim de ampliar a aprendizagem dos estudantes de Pedagogia e contribuir em sua futura ação didática. Os resultados foram construtivos, pois a metodologia utilizada para subsidiar a formação, aliada a outras teorias enriqueceram os resultados da pesquisa, e para a autora, a Sequência Fedathi ampliou as possibilidades didáticas em sala de aula.

Em conformidade com esses estudos pensamos que o conceito de prática deve ser ampliado integrando teoria e prática - práxis, estabelecendo uma relação de interdependência, mas também de autonomia. E assim, o professor, pode alcançar a práxis, inter-relacionando de um lado o ideal- teórico, e de um outro lado o material - 
prático, mas para Santomé (1991) sem a separação do que seja ideal ou material, mas sempre conectados pela práxis.

Nesse movimento sobre a práxis, vimos que ao mesmo tempo que o sujeito age, ele reflete e ao refletir ele age, num processo de idas e vindas, envolvendo ação-reflexão da prática à teoria, num processo de construção mútua, infinitamente para a práxis.

Nesse sentido, falamos a seguir do momento do planejamento das oficinas, a partir das premissas da metodologia SF.

\section{O planejamento na Sequência Fedathi}

Na SF o planejamento da 'sessão didática' - termo utilizado na metodologia Sequência Fedathi-SF para assim definir mais amplamente o conceito convencional de aula - é a fase de organização didática do trabalho pedagógico, contemplando variáveis que constituem o antes, o durante e o depois da sala de aula.

É nesse momento que são considerados dois elementos fundantes da metodologia: (a) análise ambiental; e, (b) análise teórica; as quais atendem, respectivamente: i) a análise do plateau (nível de conhecimento e experiência do aluno); e, ii) escolhas do material pedagógico adequado ao lócus e ao público.

Para a realização da sessão didática, o professor estabelece o acordo didático a fim de preservar o bom andamento e a participação dos alunos nas atividades. O acordo didático - para a SF é o conjunto de preceitos que entrelaça a cumplicidade didática na sala de aula entre o tripé: professor - conteúdo- aluno e deve estar claro no planejamento, e coerente com as demandas da sala de aula e em conformidade com a realidade e as expectativas dos alunos.

Salvaguardado esses elementos iniciais, seguimos para a fase da tomada de posição, a qual é caracterizada pelo momento em que o professor lança uma situação- problema para os alunos, em forma de pergunta - ponto de partida da sessão didática in locus. A tomada de posição adota como referência o plateau. Para a Sequência Fedathi, normalmente, quando os alunos não dominam o pré-conteúdo (conteúdos que envolvem a base conceitual a ser apreendida), esse avanço necessita de mais atividades ou interpretações variadas, usando mais analogias, contraexemplos, bem como perguntas reflexivas e desafiadoras.

O uso da pergunta para a SF possibilita ao docente identificar possíveis 'erros' e verificar os resultados encontrados no sentido de encontrar a solução mais geral. Para Sousa (2015) a pergunta deve ser usada como estratégia de mediação e deve fomentar no aluno reflexão e ação para a investigação. O autor ainda destaca que caso o aluno mostre desinteresse para resolver o problema proposto, que o professor faça perguntas a ele que o coloque em situação de desafio e o estimule a buscar uma solução. 
$\mathrm{Na}$ SF os questionamentos têm papel importante na orientação do raciocínio dos estudantes, pois serve para designar as indagações dos professores aos alunos e dos alunos aos professores, e assumem o papel de mediação dialética entre professor e aluno com o objetivo de favorecer a imersão do discente à prática do docente no que se refere ao conteúdo que este pretende ensinar, sob a compreensão que o saber deixa de ser um produto e passa a ser visto como processo em constante reflexão, construção/ reconstrução e relação com o todo social.

Sousa, Lima, Santos, Lima e Borges Neto (2013, p. 28), ao vivenciarem a SF com docentes e alunos, perceberam os tipos de perguntas que os alunos faziam aos professores, e caracterizaram essas perguntas como de,

a) dúvidas: manifestam-se por parte dos alunos, geralmente no início da resolução sobre a forma de representação da resposta ou dos conceitos aplicáveis à resolução do problema ou mesmo da solicitação de que o professor, indique o caminho inicial da resolução ou resolva um problema parecido; b) reflexões: na maioria das vezes, surgem quando os alunos já conseguiram elaborar algum tipo de solução e passam a indagar se está correta, se atende às condições propostas pelo problema e se existem outras formas de resolver a questão; c) hipóteses: aparecem quando os alunos buscam o caminho para constatar ou testar se suas respostas estão realmente corretas.

Os questionamentos dos professores aos alunos são classificados por Sousa et al. (2013, pp. 26-28) de,

a) perguntas esclarecedoras: objetivam verificar o que e como os alunos estão entendendo em se tratando do problema apresentado, (...). Sua principal função é proporcionar o feedback ao professor; b) perguntas estimuladoras: têm como propósito levar o aluno a fazer descobertas. Devem estimular o pensamento criativo, podendo suscitar uma cadeia de outros questionamentos (...), a fim de conduzir a uma determinada conclusão; c) perguntas orientadoras: são aquelas em que o professor leva o aluno a tentar estabelecer compreensões e relações entre o problema e o caminho a seguir para chegar à solução.

Para a SF a pergunta auxilia no processo de equilíbrio/desequilíbrio, com a finalidade de impulsionar o aluno à investigação, e desafiá-lo a sair da sua zona de conforto e assumir o papel de pesquisador, objetivando encontrar respostas para a situação-problema apresentada pelo professor. Sousa (2015, p. 44) reforça, 
Por isso, é conveniente não fazer perguntas em que um "sim" ou um "não" sejam suficientes como respostas, nem atender às perguntas dos estudantes com esse tipo de resposta". Eles lembram ainda que no momento de mediação vale o uso de perguntas que provoquem as certezas e as dúvidas dos estudantes diante do problema em questão.

Há um investimento em torno da pergunta por ser considerada fundamental no ensino e para aprendizagem do aluno, seja a pergunta que o professor faz aos alunos, como a pergunta que os alunos fazem ao professor, é preciso observar com cuidado para garantir que as respostas não se reduzam a uma única palavra - sim ou não. A seguir a figura 1 apresenta elementos que compõem a SF.

Figura 1. Etapas da preparação da Sessão didática.

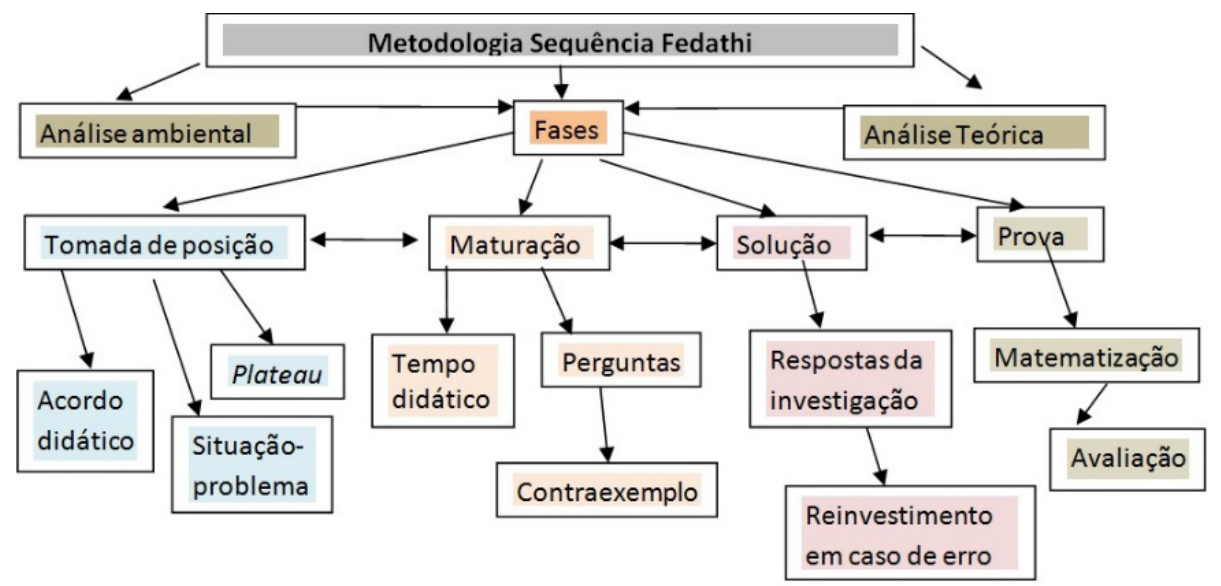

Fonte: elaboração própria.

A figura 1, acima apresenta um resumo dos princípios teórico-metodológicos que constituem a Sequência Fedathi (SF) visando: (a) preparar os docentes para a melhoria da prática pedagógica; (b) mudança de postura desse profissional em sala de aula; (c) uma formação continuada de qualidade; e, (d) contribuições para superação dos obstáculos que impeçam a compreensão de conceitos matemáticos durante o processo de aprendizagem do aluno. Sobre a figura 1, as fases estão em constante movimento didático, e podem mudar de lugar, a depender do professor e aluno, e do modelo didático em pauta. 


\section{Ensinar e aprender Matemática: refletindo sobre modelos}

O professor desenvolve concepções, crenças, conhecimentos e saberes ao longo da carreira profissional e não importa com que qualidade venhamos a desenvolver os programas de formação, pois sempre os professores estarão processualmente em eterno aprendizado. Apresentamos aqui uma breve reflexão sobre a polarização de modelos, de concepção epistemológica, pois temos de um lado o Instrucionismo (tradicional) e de outro Construtivismo (Intuicionista). Estudos sobre esses dois modelos de salas de aula reforça que cada um desses modelos o professor assume um papel diferenciado.

Na sala de aula tradicional, o professor (a) dá aos alunos vários exemplos do conceito a ser aprendido; (b) define o conceito; (c) insere no processo vários exercícios de fixação; e depois, por meio de uma "avaliação objetiva", (d) verifica se os alunos aprenderam. Já o outro modelo de sala de aula, caracterizado como intuicionista, acontece que: (a) os alunos são os protagonistas; (b) o professor organiza as atividades estruturadas; (c) o professor trabalha o erro com contraexemplos; (d) estimula a criação de outros conceitos; (e) estimula outras formas de trabalhar o conteúdo; e, (f) avalia os alunos por meio dos diálogos e projetos. Esse último modelo se coaduna com as premissas da SF

Qual é o papel que o professor deve assumir, de um professor tradicional ou intuicionista?

D'Ambrosio (1993) aponta algumas características relevantes para esse profissional que vai atuar no século XXI, que são: (i) a visão do que vem a ser a Matemática; (ii) do que constitui a atividade Matemática; (iii) do que constitui a aprendizagem Matemática; (iv) do que constitui um ambiente propício à aprendizagem Matemática. Para enfatizar esse modelo de ensino Mendes (2001, p. 23) enfatiza o caráter investigatório do processo de construção do edifício matemático, a fim de alertar os estudiosos dessa área a pensarem mais sobre a elaboração, a testagem e, a avaliação de atividades de ensino.

Sabemos que a formação docente passa por diversos desafios de formar professores que dominem não só conteúdos, mas metodologias, teorias e recursos pedagógicos. O professor deve aprender a aprender para aprender a ensinar.

No entanto, é comum cada vez mais, as formações continuadas/contínuas se fortalecendo a partir dos resultados das avaliações externas, e vão substituindo a ideia de formar pelo sentido, para a de preparar para o mercado.

Sobre isso, Santos (2012, p. 39) destaca que é nesse cenário que as propostas mais progressistas ou mais conservadoras no sentido de democratização da educação têm colocado ênfase na formação do professor, e representa a implementação das políticas públicas elaboradas em nível de governo. 


\section{A formação de matemática e as oficinas pedagógicas: uso da SF}

A formação desenvolvida por meio de oficinas pedagógicas, e planejadas seguindo os pressupostos da metodologia Sequência Fedathi (SF), foi baseada no desenvolvimento das variáveis que constituem as sessões didáticas. Nisso, as oficinas de matemática foram pensadas para o melhor desenvolvimento dos conteúdos pelos professores em sala de aula.

Inicialmente as oficinas foram realizadas na sala de aula convencional e, depois seguiram para o laboratório de informática, a fim de realizar atividades na plataforma TelEduc(http://teleduc4.multimeios.ufc.br) a qual possibilitou: a) trabalhar as atividades a distância; e, b) o contato diário com os formadores e coordenadores.

A carga horária do curso foi de $64 \mathrm{~h} / \mathrm{a}$, distribuídas em $24 \mathrm{~h} / \mathrm{a}$ presenciais e $40 \mathrm{~h} / \mathrm{a}$ online. Foram planejados seis (6) sessões didáticas, sendo quatro (4) para efetivos trabalhos de conteúdos matemáticos, e dois para compreensão das variáveis locais - hipóteses levantadas, análises do conteúdo, e desenvolvimento dos conhecimentos prévios (plateau). Para o bom desempenho das oficinas era necessário conhecer o conteúdo, e ter conhecimentos básicos sobre a ferramenta tecnológica (TelEduc) usada na formação.

Logo no primeiro encontro, os formadores e cursistas firmaram o acordo didático sobre como seriam as atividades formativas, como deveriam participar. Os formadores esclareceram as condições necessárias para que as ações fossem desenvolvidas com competência, dinamismo e responsabilidade, e os cursistas falaram de suas expectativas. O acordo didático é relevante, pois esse estabelece regras didáticas e fortalece o trabalho pedagógico, esclarecendo que papel cada sujeito deve assumir diante do trabalho pedagógico, colaborando também na análise do plateau (nível cognitivo), a partir de atividades iniciais.

Os conteúdos matemáticos abordados envolviam os blocos: grandezas e medidas, espaço e forma, números e operações e tratamento da informação (estatística). Durante a formação, foi possível identificar 'erros' nas respostas dos cursistas as situações- problema, para a SF os erros não são pensados no sentido de 'punir', 'medir', mas para proporcionar um reinvestimento, a partir da concepção de avaliação na SF que é pensada como instrumento de validação da aprendizagem, colocando em 'xeque' o ensino, com a finalidade de reorganização/reinvestimento para as próximas situações de aprendizagens. Durante as oficinas, a avaliação dos cursistas se deu pelo desempenho construtivo na manipulação dos materiais didáticos (digitais e analógicos), e na (re)elaboração dos conceitos, durante a realização das atividades, como: apresentação de seminários e vídeo-aulas.

Sobre o 'erro' os formadores compreendiam como se revelavam os processos de raciocínio e as superações necessárias para a construção do conhecimento 
lógico-matemático, e logo contribuíam para o reinvestimento na aprendizagem. Assim, os obstáculos conceituais eram trabalhados pelos cursistas e mediados pelos formadores, a fim de levá-los a "pensar para aprender a fazer fazendo o que ainda não sabe fazer, mas pode aprender".

Frente a alguns depoimentos dos cursistas retirados dos fóruns de discussão na plataforma TelEduc, destacamos um a seguir, por apresentar conscientização sobre o fazer pedagógico, na escola

o curso nos mostrou que podemos mudar esse pensamento de aprendizado, tendo várias maneiras de abordagem e vários métodos de ensino, inclusive com a Sequência Fedathi que nos mostra que a mudança deve começar pelo Formador. (Cursista A)

As oficinas proporcionaram aos cursistas vivenciar a SF e compreender a importância de em sua prática pedagógica ter consciência de uma metodologia, de um dispositivo pedagógico, que pense: a) o estudo do ambiente criado pela atividade; b) organize a decomposição do tempo didático e a espera relativa ao comportamento dos estudantes; c) considere os efeitos do acordo didático; d) gerenciamento dos erros, para a formulação, sistematização e reinvestimento; e) realização das tarefas pessoais; e, f) discussão sobre os dispositivos de avaliação, que ser adequado às atividades e aos sujeitos.

\section{Os formadores e os cursistas: relações pedagógicas}

Para Nóvoa (1997) a lógica da formação continuada deve ser centrada nas escolas e deve estar centrada numa organização dos próprios professores. Para a SF a formação pode acontecer nos mais variados espaços, seja presencial ou virtual, na escola ou fora dela. Mais importante que o espaço de formação é que se fale da importância da valorização da profissão professor, condições de trabalho dignas e formação de qualidade. As formações, especialmente na área da Matemática, na visão dos professores cursistas, são sempre bem-vindas, pois eles sentem muita dificuldade em trabalhar os conteúdos matemáticos de forma prática e dinâmica, por serem na maioria originários de cursos de Pedagogia.

Os depoimentos colhidos antes, durante e depois dos encontros presenciais e na plataforma TelEduc, apontam que formadores e cursistas sentiam-se satisfeitos com a metodologia, lócus e resultados da formação. Para Santos (2012, p. 49) o que caracteriza um trabalho profissional de qualidade é a realização de uma boa prática, e só existe boa prática com sólida formação teórica, e isso nos remete a discussão inicial sobre a importância da práxis. 
A pesar dos obstáculos enfrentados pelos cursistas para comparecerem as oficinas presenciais, tivemos o número de concludentes maior que o esperado. $O$ formador A, responsável pelo bloco de Tratamento da Informação (Estatística) destaca que,

A metodologia Sequência Fedathi aplicada no curso de formação foi de extrema importância para o meu enriquecimento acadêmico e profissional no ato de planejar a oficina (antes, durante e depois das atividades aplicadas em sala). (...) Sobre o conteúdo, metodologia, recursos etc parabenizando a todos da importância da Universidade Federal do Ceará - Faculdade de Educação que está mais atuante e próximo aos participantes e futuros participantes do mundo da educação matemática. (Formador A)

O formador A, ao relatar sua experiência e seus sentimentos sobre a metodologia SF, destaca que suas impressões são fundamentadas a partir das análises dos depoimentos dos cursistas na plataforma TelEduc. Já o cursista B, mais efetivamente enfoca as dificuldades vividas e questões sobre o tempo didático, ressaltando que não foi suficiente para desenvolver mais efetivamente as ações pedagógicas, e ressalta,

o curso foi formado por uma grande equipe de professores de grande qualidade o que na minha concepção nos trouxe bastante conhecimentos para que possamos ter novas metodologias para trabalhar em sala de aula, o que infelizmente não foi muito bom foi a questão do tempo devido ter sido muito rápido, mas espero que no próximo haja uma carga horária maior. (Cursista B)

O formador B destaca a importância de uma formação pautada na práxis, por entender a importância do sentido para o fazer pedagógico.

escolhi trabalhar com os conceitos a respeito da localização. Como o foco eram atividades práticas para que os professores pudessem reproduzi-las em sala de aula me apropriei de materiais de fácil acesso aos professores para fundamentar minha oficina. (Formador B)

As oficinas seguiram as fases da Sequências Fedathi: tomada de decisão, maturação, solução e prova, distribuídas em dois momentos: o primeiro momento - foi o planejamento das atividades presenciais e a distância entre os professores e os alunos da graduação e pós-graduação envolvidos, assim como a preparação do ambiente virtual de aprendizagem - TelEduc/Multimeios. No segundo momento - a realização experimental da proposta, em que aconteceram os momentos presenciais e a distância. 
Para melhor acompanhar os cursistas, optamos por dividir o total de inscritos em 4 grupos, cada grupo ficou com aproximadamente 50 cursistas. Cada grupo ficou sob a responsabilidade de um formador (pós-graduando) que contava com o auxílio de um bolsista (graduando), e todos sob a égide dos coordenadores do projeto.

Nessa direção, o formador C, assinala

Não poderia deixar de enfatizar os vários momentos produtivos que tivemos principalmente presenciais com a Oficina sobre Números e Operações voltados ao ensino de alunos do Ensino Fundamental da Educação Básica. Não foi um tema fácil diante da estrutura do curso, pois junto da falta de tempo para aprofundarmos o assunto em cada turma, as discussões normalmente se encaminhavam para o ambiente virtual e que uma série de outras questões poderiam ser levantadas e aprofundadas. (Formador C)

Essa reflexão nos encaminha a pensar sobre o tempo de incertezas porque passa a educação brasileira, o professor de modo geral, sente a necessidade da mudança de seu comportamento pedagógico, de domínio de metodologias inovadoras, mas não é fácil definir o caminho a ser percorrido, pois em grande medida os professores servem a um currículo esvaziado de sentido, redundantes que só revelam a escassez e inabilidades de práticas pedagógicas. E nisso, o formador $\mathrm{C}$ reforça que

Ao ler e escutar os relatos dos cursistas, muito me deixa otimista a condição deles próprios perceberem que o professor deve constantemente está procurando rever suas práticas e evitando de ser um profissional que apenas 'repassa' os conteúdos com vistas a novos conhecimentos, mas incentiva a própria descoberta pelos alunos. Um outro aspecto importante a destacar, está no fato de termos atuado numa oficina em que sugestões e modelos não eram fornecidos aos cursistas, e sim rediscutido conceitos, ideias, procedimentos e práticas (...). (Formador C)

O formador $\mathrm{C}$ a partir dessas reflexões revela que as discussões, orientações e sugestões vivenciadas no curso favoreceram aos professores uma análise crítica das atitudes de suas antigas práticas, revelando que o tratamento dado à Matemática como difícil, incompreensível, inacessível, cheio de fórmulas, 'transformou' seu pensamento, e consequentemente, sua abordagem ao lidar com a matemática em sala de aula.

A partir dessa formação vimos que foi possível refletir sobre o exercício da docência em matemática, nos níveis da Educação Infantil, Ensino fundamental dos anos iniciais e EJA e articular alunos da Pós-Graduação para o desenvolvimento de atividades na 
graduação. Produzimos material no formato e-book para socialização e divulgação no site institucional do grupo de pesquisa G-tercoa: http://tercoa.ufc.br.

\section{Considerações}

Apresentamos uma síntese do que é uma ação formativa fundamentada na metodologia de ensino Sequência Fedathi. Procuramos ressaltar os principais elementos (princípios e pressupostos), destacando os que devem ser efetivamente mais explorados, destacamos a importância do trabalho pedagógico envolvendo: o antes, o durante e o depois de uma aula, bem como a postura do professor de matemática, como eixo central, visando sempre uma relação de aprender a aprender considerando o tripé: professor-conhecimento-aluno, para o aprender para ensinar.

A essência da formação nos pressupostos da metodologia da SF está em otimizar o processo de ensino de maneira a levar os alunos a desenvolverem o raciocínio matemático, levando-os a construírem seus conceitos a partir das experimentações e constatações feitas durante todo o processo de desenvolvimento da metodologia, de modo a vivenciarem a mesma atmosfera do trabalho desenvolvido pelo matemático.

Umas das dificuldades dos professores da educação básica em participar de um processo de formação continuada, é o processo de liberação das redes de ensino, mas a ida deles à universidade foi positiva, do ponto de vista formativo. Os principais beneficiados com essas formações, não são os docentes, mas sim os alunos, pois esses profissionais mais motivados, valorizados e qualificados passam a pensar com mais criatividade sobre a educação e consequentemente, melhoram sua práxis.

Foi importante perceber os sentimentos que os cursistas expressavam durante a formação, ficou evidente que eles valorizavam: (a) o retorno à universidade; (b) o acoIhimento dos cursistas pelos professores e coordenadores; (c) a aproximação da prática escolar com as práticas pensadas na academia; e, (d) a importância da metodologia SF na formação docente, a partir de suas próprias demandas.

Dada as inovações e exigências a partir das modificações pelas quais a educação deve passar a partir de questões sociais e culturais, a necessidade de formação de professores reflexivos e críticos, se tornou de grande relevância contemporânea, assim reforçamos a importância de cursos de formação docente, centrados e estruturados em uma metodologia como a SF, na busca pelo fortalecimento do fazer pedagógico e da valorização da profissão professor.

Nota: Este artigo faz parte de um projeto de extensão realizado em 2016, renovado em 2017 na Faculdade de Educação-FACED da Universidade Federal do Ceará - UFC. O projecto integra duas bolsas de Iniciação à extensão da pró-reitoria (PREX/UFC), e conta com a participação do eixo de pesquisa ensino de Matemática, por meio de seus estudantes e pesquisadores. 


\section{Referências Bibliográficas}

Bachelard, G. (2002). A epistemologia. Lisboa: Edições 70.

Brasil. (2014). Plano Nacional de Educação 2014-2024. Lei n. ${ }^{\circ}$ 13.005. Brasília: Edições Câmara. 86 p. Disponível em: http://www.observatoriodopne.org.br/uploads/reference/file/439/documentoreferencia.pdf. Acesso em 10/08/2017.

Brasil. (1997). Secretaria da Educação Fundamental. Parâmetros Curriculares Nacionais: Matemática. Brasília: MEC/SEF. Disponível em: http://portal.mec.gov.br/seb/arquivos/pdf/livro03.pdf. Acesso em 10/08/2017.

Carr, W. (1996). Una teoria para la educación: hacia una investigación educativa crítica. Madrid: Morata.

D’Ambrosio, B. S. (1993). Formação de professores de matemática para o século XXI: o grande desafio Pró-posições 4 (1), 35-41.

Freire, P. (1987). Pedagogia do oprimido. Rio de Janeiro: Paz e Terra.

Lima, I. P. (2007). A Matemática na Formação do Pedagogo: oficinas pedagógicas e a plataforma Teleduc na elaboração dos conceitos. Fortaleza: UFC. (Tese de Doutorado).

Fernandes, S. \& Conceição, Ana. C. (2013). Pré-cálculo e a formação inicial de professores de Matemática: resultados preocupantes de um teste diagnóstico, Revista Lusófona de Educação 25, 135-155

Lopes, A. C. (2012). A qualidade da escola pública: uma questão de currículo? In. Viana, F. S. (org.). A qualidade da escola pública no Brasil. Belo Horizonte: Mazza Edições.

Mendes, I. A. (2001). O uso da História da Matemática: reflexões teóricas e experiências. Belém: EDUEPA..

Nóvoa, A. (org.) (1997). Os professores e sua formação. Lisboa: Dom Quixote/llE.

Polya, G. (1978). A arte de resolver problemas: um novo aspecto do método matemático. Rio de Janeiro: Inter-ciência

Pimenta, S. G. (1991). Profissão professor. Porto: Porto Editora.

Santomé, J. T. (1998). Globalização e interdisciplinaridade: o currículo integrado. Porto Alegre: Editora Artes Médicas Sul Ltda.

Santos, L. L. (2012). A qualidade da escola pública: A contribuição dos professores e de sua formação. In Viana, F. S. (org.). A qualidade da escola pública no Brasil. Belo Horizonte: Mazza Edições.

Santos, M. J. (2007). Reaprender frações por meio de oficinas pedagógicas: desafio para a formação inicial. Dissertação de Mestrado em Educação. Fortaleza:Universidade Federal do Ceará - FACED/ UFC.

Sousa, F. E. E. (2015). A pergunta como estratégia de mediação didática no ensino de matemática por meio da Sequência Fedathi. Fortaleza: Fortaleza: Universidade Federal do Ceará- FACED/UFC.

Sousa, F. E. E., et al (orgs.). (2013). Sequência Fedathi: uma proposta para o ensino de matemática e ciências. Fortaleza: Edições UFC. 
Maria José Costa dos Santos Professora Adjunta da Universidade Federal do Ceará-UFC. Líder do Grupo de Pesquisa Tecendo Redes Cognitivas de Aprendizagem (G-TERCOA CNPq). Pós-doutoranda na Universidade do Estado do Rio de Janeiro em

Educação -PropEd; bolsista Capes/PNPD

Email: mazeautomatic@gmail.com

Correspondência

Maria José Costa dos Santos

Rua Holanda Amaral Campos, 90

Guaribas - Eusébio- Ceará-Brasil

CEP: 61760-000

Data de submissão: Janeiro 2017

Data de avaliação: Abril 2017

Data de publicação: Dezembro 2017 